\title{
PARAÍSO E INFERNO NA VISIÓN DE DON TÚNGANO (VISÃO DE TÚNDALO): UM PERCURSO PARA A SALVAÇÃO
}

\section{PARADISE AND HELL IN VISIÓN DE DON TÚNGANO (TÚNDALO VISION): A ROAD TO SALVATION}

\author{
Adriana Maria de Souza Zierer ${ }^{1}$
}

\begin{abstract}
Resumo: O objetivo deste artigo é apresentar os caminhos para a salvação de Don Túngano ou em português, do cavaleiro Túndalo na sua experiência ao Além-Túmulo. A narrativa, originalmente uma viagem imaginária produzida no século XII, trata da trajetória do personagem central pelos caminhos infernais e paradisíacos para chegar à salvação. São mostrados os elementos da narrativa, que circulou nos atuais Espanha e Portugal no final da Idade Média e início da Moderna, bem como a sua influência nas artes, como através da pintura intitulada Visio Tondaly, de um seguidor de Bosch, produzida no século XVI.
\end{abstract}

Palavras-chave: Visión de Don Túngano, Literatura, Arte, salvação, Bosch.

Abstract: The purpose of this paper is to present the way for the salvation of Don Túngano or in Portuguese, the knight Túndalo (Tnugdal) in his experience beyond grave. The narrative, originally an imaginary journey produced in the twelfth century, deals with the trajectory of the central character by hellish and heavenly ways to reach salvation. Elements of the story that circulated in today's Spain and Portugal are shown in late Middle Ages and early modern period and also its influence in the arts, for example, through the work entitled Visio Tondaly, painted by a follower of Bosch, in the sixteenth century.

Keywords: Visión de Don Túngano (Vision of Tngudal), Literature, Art, salvation, Bosch.

\section{Introdução}

A Visão de Túndalo ou Visión de Don Túngano é uma viagem imaginária que teve uma grande circulação na Europa Ocidental, entre os séculos XII a XVI. A narrativa discorre sobre o percurso de um cavaleiro de boa linhagem, porém pecador, que não se preocupava com a salvação da sua alma. Também "ni curaba jamás de ir a la iglesia, ni dar a los pobres por Dios, nem ia às missas" (VT, 2013). Um dia se sente mal e vive uma experiência de quase-morte quando sua alma sai do corpo e é acompanhada por um anjo para conhecer os espaços do além-túmulo, indo primeiro aos espaços infernais e depois ao Paraíso. Na volta, Don Túngano (ou Tnugalus, Tnugdal, Túndalo, Tondal, entre outras acepções) se regenera e conta a sua experiência.

O relato, que influenciou a Divina Comédia de Dante Alighieri, faz parte de um longo conjunto de viagens ao Além desde a Antiguidade, que visavam explicar o destino das almas após a morte. A obra, escrita originalmente em latim ou gaélico por um monge irlandês, tem os manuscritos mais antigos nesse primeiro idioma, com cerca de cento e cinquenta e quatro

\footnotetext{
${ }^{1}$ Doutora em História Medieval. Professora da Graduação e do Mestrado em História, Ensino e Narrativas da Universidade Estadual do Maranhão (UEMA). Docente do Mestrado em História Social da Universidade Federal do Maranhão (UFMA). Estágio Pós-Doutoral na École des Hautes Études en Sciences Sociales (2013-2014), junto ao Groupe d'Anthropologie Historique de l'Occident Médiévale (GAHOM), com apoio da CAPES. É uma das coordenadoras dos seguintes laboratórios de pesquisa: Brathair - Grupo de Estudos Celtas e Germânicos e Mnemosyne - Laboratório de História Antiga e Medieval. É membro do Instituto de Cultura Celta (Portugal), do Instituto de Estudios Celtas (Espanha) e do Centro Internacional de Estudios Celtas (CIEC) (Portugal, Espanha e Brasil).
} 


\section{Notandum 42 set-dez 2016 - CEMOrOC - Feusp / IJI-Univ. do Porto \\ DOI: http://dx.doi.org/10.4025/notandum.42.1}

manuscritos conservados e mais onze que foram perdidos (PALMER, 1992, p. 168, nt. 3) ${ }^{2}$.

Ela foi logo traduzida para os idiomas vernáculos com versões em francês (onze) ${ }^{3}$, alemão (dez), holandês (quatro), italiano (quatro), catalão (três) ${ }^{4}$, servo-croata (duas), português (duas), inglês (uma), gaélico (uma) ${ }^{5}$ entre outros idiomas, com vários manuscritos em cada versão ${ }^{6}$, tendo sido traduzida para quinze diferentes línguas.

Sabemos pouco sobre Marcus, que compôs a Visio. Além de sua origem, a Irlanda, sabemos que no momento de composição do relato estava em Regensburg, na Alemanha e compôs o relato para a abadessa do mosteiro de Saint Paul, Gilsa ou Gisela.

A narrativa também teve uma grande circulação a partir da invenção da prensa móvel e na Alemanha circularam várias edições impressas entre o fim do século XV e início do século XVI. Essas edições foram compostas tanto na língua alemã (vinte), quanto em latim (cinco), algumas das quais ilustradas por um conjunto de vinte ou vinte e uma xilogravuras, inspiradas no texto conservado do Speculum Historial, de Vincent de Beauvais (PALMER, 1992, p. 160) ${ }^{7}$. Também houve cinco edições impressas na Holanda.

\section{A Circulação da Visio na Espanha e em Portugal}

Miquel y Planas (1914, p. 33-118) editou três versões catalãs da Visio Tnugdali ${ }^{8}$ A primeira proveniente do códice Escorial, com o título de La Visio del Monestir de Clares Valls (fols. 69-86) (versão A) ${ }^{9}$. A segunda, Historia de Gaudal (versão B) ${ }^{10}$, estudada por ele com base no Códice Hisp. 66, fólios $102-114^{11}$ e a terceira, a Historia de Tuglat (Versão

\footnotetext{
${ }^{2}$ Este número de manuscritos latinos pode variar um pouco. Segundo Wieck (1990, p. 3) seriam cento e cinquenta e quatro, mais quatorze que foram perdidos.

${ }^{3}$ Dessas onze versões, três foram impressas por Friedel em 1907, segundo Cavagna (2010, p. 9)

${ }^{4}$ De acordo com Miquel y Planas (1914, p. X. Ver também p. 268-274). Foram produzidas no final da Idade Média. Mas há ainda outras edições, além dessas. Conferir nota 8.

5 A edição em gaélico é do século XVI, manuscrito H-3-18, que se encontra no Trinity College, em Dublin. Para consultar o texto em gaélico, ver a edição de Kuno Meyer Aisling Tundail (Electronic edition compiled by Beatrix FärberProof corrections by Hilary Lavelle and Beatrix Färber). Disponível em: http://www.ucc.ie/celt/published/G207009A/index.html . Acesso em 10/01/2014. O texto também está publicado na Vision de Tondal, edição de Friedel (1907), p. 87-144.

${ }^{6}$ Ver Quadro dos manuscritos e versões da obra em diferentes idiomas em PALMER, 1982, p. 1.

${ }^{7}$ Vincent de Beauvais resumiu a história de Túndalo e a acrescentou na sua enciclopédia, cuja parte dedicada ao Speculum Historial contém trinta e dois livros. O relato do cavaleiro é conservado no livro 28, com o título De Raptu Animae Tundali et eius Visione. Muitos textos da visio em vernáculo, tanto manuscritas como impressas, foram inspirados nessa versão.

8 Ver também o estudo do editor sobre essas versões, p. 268-274. Além dessas edições parece haver mais material da Visio. Segundo Antonio Chas, a versão peninsular mais antiga conservada, provavelmente de fins do século XIV, é o manuscrito 99-37 do Arquivo e Biblioteca capitular de Toledo, em mal estado de conservação. (CHAS AGUIÓN, 2009, p. 18.) Para outras informações desse manuscrito, ver: Libro de Túngano; Visión de un caballero de Ibernia. Catálogo Hipertextual de Traducciones Anónimas al Castellano. Disponível em: http://www.catalogomedieval.com/busqueda.php?id=225 ; acesso em 05/08/2015.

${ }^{9}$ Versão publicada por Miquel e Planas em Llegendas de L'Altra Vida, Barcelona, 1914, p. 35-69.

${ }^{10}$ Versão publicada por Miquel y Planas, 1914, p. 71-93.

${ }^{11}$ Com mutilação nos fólios 112-113 (RODRÍGUEZ BARRAL, 2003, p. 116).
} 


\section{Notandum 42 set-dez 2016 - CEMOrOC - Feusp / IJI-Univ. do Porto DOI: http://dx.doi.org/10.4025/notandum.42.1}

C) ${ }^{12}$, localizada no Archivo de la Corona de Aragón, manuscrito 83 de Saint Cugat del Vallés (fls. $102 \mathrm{v}-127 \mathrm{v})^{13}$.

A narrativa também esteve entre os primeiros livros impressos na Espanha, como, por exemplo, na versão publicada em Toledo, intitulada História Del Virtuoso Cavaleiro Don Túngano. A edição de 1508 se perdeu e poucos anos após foi composta outra, em 1526. A seguir é possível observar a página inicial desta última edição, cujo título ressalta o fato de Túngano ser virtuoso, isto é, ter se tornado um bom cristão após o seu retorno do Além.

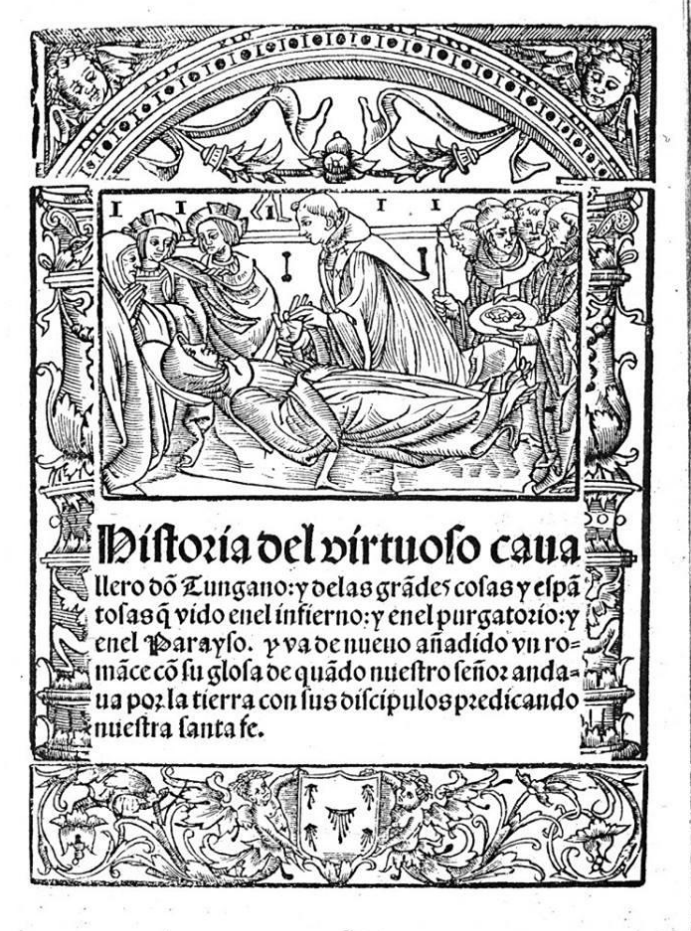

Figura 1. História Del Virtuoso Cavaleiro Don Túngano. Toledo, 1526, frontispício. Disponível em:

http://commons.wikimedia.org/wiki/File:Historia_del_virtuoso_caballero_don_T\%C3\%BAngano_Toledo, 1526 .jpg (acesso em 10/01/2014)

A xilogravura (fig. 1) apresenta uma cena que remonta tanto ao começo da viagem (quando Túngano se sente mal e cai no chão, numa morte aparente) quanto ao final do relato quando, após o cavaleiro ter retornado do Além, pedir para tomar a hóstia e se confessar. Vemos na figura um religioso que segura a sua mão e outro com um prato estendido com algum alimento, alusão à hóstia e seu aspecto espiritual (corpo de Cristo).

Também são mostrados vários outros personagens na imagem, tanto homens quanto mulheres bem vestidos e vários outros clérigos, o que parece destacar a importância do cavaleiro e a preocupação de muitas pessoas com ele e com a salvação da sua alma. É bom lembrar que no período medieval o mundo terreno era considerado um lugar de passagem, segundo o pensamento da Igreja, sendo o ser humano um homo viator a caminho do mundo

\footnotetext{
${ }^{12}$ Versão publicada em Miquel e Planas, 1914, p. 95-118.

${ }^{13}$ Para visualizar o fólio 91r desse manuscrito, ver GARSABAL, Jordi. Del Más Allá al Nuevo Mundo. Les Viajes Medievales y las Capitualciones de Colón en el Archivo de la Corona de Aragón. Aragón: Ministerio de Educación, Cultura e Deporte, 2013, p. 29.
} 
espiritual. A morte era algo esperado e o maior temor era sofrer uma morte súbita sem se confessar, daí a necessidade de absolvição pelos religiosos para que os cristãos atingissem o Paraíso.

Na composição desta Visio, o papel dos clérigos, representados pela figura de um monge irlandês, é fundamental. A narrativa foi vivenciada por um leigo e reinterpretada por um monge irlandês, Marcus, que redigiu o relato em Regensburg, na Alemanha para a abadessa G. (Gisela), do mosteiro de Saint Paul, como já mencionado. Marcus pertencia ao Mosteiro de S. Jacques, fundado por monges irlandeses (PONTFARCY, 2010, p. XXXIX$\mathrm{XL})$.

Segundo Le Goff, esses relatos de viagens imaginárias são originários de três tradições (LE GOFF, 1994, p. 132-133): 1. Descidas no Inferno e Julgamentos. ex: Eneias no Inferno quando ouve gritos à esquerda e observa os Campos Elísios à direita; Gilgamesh na sua epopeia vai ao Inferno, 2. Apocalipses Judaico Cristãos, elaborados entre os séculos II a.c e III d.c (ex: Apocalipse de Paulo) 3. narrativas pagãs e principalmente irlandesas de viagens ao Outro Mundo (provenientes da tradição oral, através os imrama, como The Voyage of Bran, son of Febal to the Land of the Living).

Essas histórias da tradição oral eram relidas pelos monges, como Marcus, o irlandês quase desconhecido que compôs o relato de Túndalo. Os testemunhos eram escritos em latim, faziam associações à Bíblia e à literatura apocalíptica. Essas narrativas explicando os espaços do pós-morte serviam de modelo de comportamento eclesiástico e também laico, pois eram transmitidas durante os sermões aos leigos.

O grande período de composição das Visões foi o século XII, sendo a mais conhecida delas a Visio Tnugdali. O objetivo da narrativa era mostrar aos fiéis as corretas normas de comportamento apelando para a memória, para que fossem lembradas, contadas e seguidas por todos, com o objetivo que pudessem atingir o Paraíso.

Sob o propósito da experiência do cavaleiro, de acordo como relato produzido em Toledo, a Visión de Don Túngano (1526):

Y como nuestro Señor Jesucristo es tan piadoso quiso que este hombre, maguer fuese tan pecador que dejase a nosotros ejemplo entre todos los que vivimos en este mundo, de las cosas y penas que vio y pasó porque nos guardásemos de no hacerlas y obrarlas" (VT, 2013, p.1, grifo nosso).

A ênfase de que Túndalo serviria como exemplo do que não deveria ser feito aponta um forte caráter educativo no relato, transformando-o num verdadeiro manual de comportamento cristão para se atingir a salvação.

Após ver e sentir as torturas infernais, Túndalo (ou Túngano) conta a sua experiência aos demais, pede para tomar a hóstia (corpo de Cristo, para se purificar; ver a figura 1) e passou a ter uma vida exemplar para atingir o Paraíso, como pode ser observado no trecho a seguir:

Y después este caballero Túngano partió e hizo limosnas de todas las cosas que tenía y las dio a los pobres y enmendó su vida que bien amonestada y espantada venía de las penas que sufriera y viera. Y muy grande sabor, placer y alegría tenía de los grandes bienes, deleites y cosas que en la Gloria viera (VT, 2013, p. 1, grifos nossos). 


\section{Notandum 42 set-dez 2016 - CEMOrOC - Feusp / IJI-Univ. do Porto \\ DOI: http://dx.doi.org/10.4025/notandum.42.1}

O trecho reforça que ele "emendou" a sua vida e repartiu as suas riquezas com os pobres. Portanto, o personagem central passa do seu momento inicial na narrativa, quando é apresentado como membro da nobreza (cavaleiro de boa linhagem), forte, bonito, mas fútil, por se preocupar somente com os prazeres mundanos, para um exemplo de bom cristão que dava esmolas aos pobres, frequentava as missas e tinha um comportamento adequado como cristão. Um verdadeiro modelo a ser seguido pela sociedade.

Essa viagem imaginária está associada a preocupações do século XII, como a Reforma Gregoriana, que marcou a importância da Igreja enquanto instituição, ao mesmo tempo em que exigiu um comportamento mais puro dos clérigos, instituindo o celibato obrigatório e proibindo a simonia (venda de cargos religiosos). Também estabelece a ideia do livre arbítrio como fundamental para a obtenção da salvação, um aspecto que é bastante ressaltado na Visio.

O autor irlandês, Marcus, de quem temos poucas informações, demonstra ser partidário da Reforma Gregoriana e dos Mac Carthy e da preeminência de Cashel. No prólogo de sua obra afirma que na Irlanda havia vinte e três cidades, cujos abades dependiam de dois arcebispados, o de Armagh, situado no norte, e o de Cashel, no sul que seria o mais "eminente" (VT, 2010, p. 8-9). Segundo Pontfarcy essa frase denota a preferência do autor pelos Mac Carthy, que inicialmente haviam governado todo o Munster, província do sudoeste da Irlanda. Depois ocorre uma divisão do poder, com lutas entre Mac Carthy (sul) e O' Brien (norte). Nesse momento de ascensão dos O’Brien, o arcebispado de Cashel passa a ser subordinado ao de Armagh.

No prólogo da Visio, Marcus descreve dois reis do Munster, que teriam sido antes inimigos e que depois viraram amigos, os quais se encontravam num lugar próximo do Paraíso. Sublinha a generosidade de um deles, Donato, do clã dos Mac Carthy (PONTFARCY, 2010, XLII), que teria dado todos os seus bens aos pobres (VT, 2010, p. 114115) Essa uma atitude caridosa também é adotada por Túndalo/Túngano ao final da narrativa. Historicamente, Donato foi irmão de Cormac, rei do Desmond (1124-1138).

Em Portugal a Visão de Túndalo foi traduzida entre o final do século XIV e o início do século XV, com duas traduções em manuscritos, nos códices 244 e 266 por monges do mosteiro de Alcobaça. O século XV é um importante período de circulação da obra não só em manuscritos, como os de Portugal, mas também nos primeiros livros impressos (incunábulos) em outros países europeus, como na Inglaterra, França, Alemanha, Holanda e Espanha.

A Visão de Túndalo também influenciou as artes plásticas. Um importante artista influenciado por esta Visio é Bosch, cujas imagens de torturas infernais estão diretamente relacionadas ao relato, que ele conheceu (BOSING, 2006), pois a Visio teve ampla circulação na Holanda tanto em manuscritos quanto em textos impressos. Isso demonstra a atualidade e importância da obra ainda na Baixa Idade Média, período do Cisma do Ocidente, com dois papas na Cristandade, em Roma e Avignon, da Peste Negra e do medo da morte.

Os relatos do século XII falam somente do Inferno, dividido em Superior e Inferior, e do Paraíso. Já nos relatos do século XV o Antigo Inferno Superior passa a ser o Purgatório. Além da Visión de Don Túngano (ver figura 1), entre outros textos do século XV, o códice 244 da versão portuguesa também fala explicitamente desses três espaços: "Começase a Estoria dhuun Caualeyro a que chamauan Tungulu ao qual foron mostradas uisibilmente [...] todas as penas do inferno e do purgatorio. E outrosi todos os beens e glorias que ha no sancto parayso". (VT, 1895, p. 101, grifo nosso). 


\section{Notandum 42 set-dez 2016 - CEMOrOC - Feusp / IJI-Univ. do Porto \\ DOI: http://dx.doi.org/10.4025/notandum.42.1}

Os espaços do Além neste período podem ser caracterizados, de maneira simples, por Inferno (local da danação eterna dos pecadores), Purgatório (lugar intermediário, onde aqueles que haviam cometidos pecados "leves" sofreriam castigos antes de irem ao Reino Celeste) e Paraíso (dedicado aos puros, lugar de felicidade e bem-aventurança divina, com a presença do Criador). Além desses espaços havia ainda o Limbo das Crianças não batizadas e o Limbo dos Patriarcas (BASCHET, 2006, p. 394-408).

É possível perceber o papel da oralidade no texto. Há uma conversa permanente entre anjo e Túndalo, constituindo numa espécie de relação entre professor e aluno. A cada tormento, o cavaleiro pergunta por que cada pecador sofre o pecado e o anjo lhe responde, admoestando-lhe que evitasse aqueles pecados quando voltasse ao seu corpo para que pudesse atingir a salvação.

É muito enfatizado que Túndalo deveria "contar" a sua experiência aos outros quando voltasse ao seu corpo. Percebe-se também vários "índices de oralidade" no texto (ZUMTHOR, 1993) palavras como ouvir, contar, dizer, e várias passagens referentes a sons, bons no Paraíso, através de cantos de pessoas e pássaros. Já no Inferno, os sons são desagradáveis, através de gritos dos humanos torturados e gemidos de sofrimentos (ZIERER, 2010 , p. 17). Esses índices mostram que a narrativa era muitas vezes transmitida oralmente pelos clérigos aos leigos em seus sermões, fazendo com que tivesse grande difusão e auxiliasse o processo de conversão.

De acordo com o códice 244 da versão portuguesa, frei Marcus havia ouvido o relato diretamente do cavaleiro e o contava à população no seu escrito, exatamente como o havia ouvido, sendo uma espécie de testemunha ocular da narrativa.

Sobre a estrutura da narrativa: Túndalo se sente mal quando estava na casa de um amigo que lhe devia dinheiro, não pôde quitar a dívida e lhe oferece um jantar. Antes de poder pegar a carne (relacionada à matéria e aos pecados corporais), ele se sente mal, cai no chão e fica desacordado durante três dias ${ }^{14}$, não sendo enterrado devido a um pouco de calor em seu peito $^{15}$.

Após sair involuntariamente de seu corpo é cercado por vários demônios que pretendem levar a sua alma ao Inferno:

[...] vio venir una gran compañía de diablos Y no tan solamente por la casa donde yacía y estaba el cuerpo, mas las plazas eran todas llenas de ellos, y cercaron el ánima de todas partes y la comenzaron a espantar muy fuertemente y decían: "Cantemos cantares de muerte y de comer de fuego. Amiga de tiniebla enemiga de luz." Y con muy gran espanto hacían y decían. "Cativa mezquina, éste es el pueblo que tú escogiste, con los cuales arderás en el fuego del infierno por siempre jamas. Y mudadas son tus nuevas de tus deleites. ¿Por qué no eres ahora soberbia como solías?, ¿por qué no haces fornicio como solías?, ¿por qué no codicias lo ajeno? y ¿por qué no vuelves escándalo entre los hombres que se maten como solías? Cinco son tus vanaglorias y vanidades, ves tu vanagloria y ves tu alegría, ves tu vano reír, ves tu vano comer, ves tu vano vestir, ves tu vano calzar que tu tenías, demás

\footnotetext{
${ }^{14} \mathrm{Na}$ versão de Toledo (1526) aparece que ficou desacordado durante quatro dias, mas na maior parte dos relatos, o tempo é três dias.

15 Tanto a versão de Toledo de 1526 quanto as duas versões portuguesas não mencionam o fato de T. se sentir mal quando ia ingerir comida, informação que aparece nas versões latinas e em alguns textos em vernáculo. A narrativa que circulou nos reinos luso e hispânico (edição de 1526) analisadas aqui já tratam logo do fato de ele se sentir mal e de sua alma ser levada aos espaços infernais.
} 


\section{Notandum 42 set-dez 2016 - CEMOrOC - Feusp / IJI-Univ. do Porto \\ DOI: http://dx.doi.org/10.4025/notandum.42.1}

que poco dabas a los pobres, ¿qué son de tu vanaglorias y locuras que tu hacías?, todo es pasado y tu penarás siempre por ellas. (VT, 2013, p. 2, grifos nossos).

Como pode ser visto na citação o pecador se desespera e é acusado pelos seres maléficos de seus pecados, como a soberba, luxúria, avareza (por não dar esmolas aos pobres), entre outros erros dos quais precisava se corrigir. Porém logo depois aparece o anjo e eles iniciam a jornada, inicialmente indo para baixo, onde o cavaleiro experimenta várias torturas, depois ascendendo aos locais paradisíacos.

No relato são descritas oito punições num lugar intermediário ${ }^{16}$ de purgação, associadas aos sete pecados capitais. $O$ texto afirma que aqueles que estão ali ainda esperam a salvação no Juízo Final. Dessas torturas, Túndalo sofre cinco punições, conforme pode ser visto a seguir (Quadro 1):

QUADRO 1. TORTURAS SOFRIDAS POR TÚNDALO/TÚNGANO ${ }^{17}$

\begin{tabular}{|l|l|l|}
\hline PECADORES & OBSTÁCULO & PUNIÇÃO \\
\hline LADRÕES & PONTE COM & $\begin{array}{l}\text { É obrigado a passar com a vaca que havia } \\
\text { roubado numa ponte com pregos, embaixo da } \\
\text { qual havia monstros. Do lado oposto, outro } \\
\text { pecador carrega um feixe de trigo. Os dois se } \\
\text { encontram no meio da ponte e se acusam } \\
\text { mutuamente de seus pecados. }\end{array}$ \\
\hline AVAROS & $\begin{array}{l}\text { BESTA } \\
\text { AQUERONTE }\end{array}$ & $\begin{array}{l}\text { Comido pela Besta. No seu interior sofre torturas } \\
\text { inflingidas por cahorros, ursos, serpentes e leões. } \\
\text { Depois os pecadores colocados no fogo e rio de } \\
\text { enxofre. }\end{array}$ \\
\hline $\begin{array}{l}\text { GLUTÕES } \\
\text { FORNICADORES }\end{array}$ & $\begin{array}{l}\text { FASISTIN } \\
\text { (FORNO) }\end{array}$ & $\begin{array}{l}\text { Almas colocadas num imenso forno, assadas, } \\
\text { como se fossem pães. }\end{array}$ \\
\hline $\begin{array}{l}\text { LUXURIOSOS } \\
\text { PRINCIPALMENTE } \\
\text { ECLESIÁSTICOS) }\end{array}$ & $\begin{array}{l}\text { BESTA } \\
\text { PÁSSARO }\end{array}$ & $\begin{array}{l}\text { Almas ingeridas por esta Besta. No seu ventre } \\
\text { engravidam. Depois são “paridas' num lago } \\
\text { gelado e ali dão a luz a serpentes que saem de } \\
\text { todas as partes de seus corpos e mordem os } \\
\text { pecadores até os ossos. }\end{array}$ \\
\hline LUXURIOSOS EM & FORJA & DEE \\
\hline
\end{tabular}

\footnotetext{
${ }^{16}$ Nas versões do século XII as punições ocorrem no Inferno Superior. Nas do século XV esse espaço passa a ser o Purgatório. É importante destacar que os que estavam ali ainda podiam se salvar.

${ }^{17}$ Para visualizar outro quadro com todos os castigos passíveis de punição na Visio Tnugdali (Visão de Túndalo), conferir BASCHET, 1981, 109. Ver também quadro relacionando os castigos com os sete pecados capitais, em ZIERER, 2010, p. 17. Sobre o quadro, espaços como a Casa de Fristin e a Forja de Vulcano não são nomeados na versão castelhana (1526) e nas portuguesas analisadas no texto. Também é importante mencionar que nas mesmas versões é omitido o fato de que a maior parte dos luxuriosos punidos são os eclesiásticos. Ver (VT, 1895), (VT, 1982-1983) e (VT, 2013).

${ }^{18}$ O nome desta Besta, Aqueronte, não aparece nas fontes portuguesas e na versão de Toledo (1526).
} 


\begin{tabular}{|l|l|l|}
\hline GERAL & VULCANO & cortadas, coadas e transformadas numa massa. \\
\hline
\end{tabular}

Entre os monstros que o torturam está a besta Aqueronte, representada normalmente como a Boca do Inferno na iconografia sobre essa visão, que engolia os pecadores. Esta besta tinha ali, como guardiões na entrada da sua boca a presença de dois heróis da mitologia irlandesa, aqui retratados com aspectos infernais, Fergus e Connal, um com a cabeça para cima e pés para baixo e o outro de cabeça para baixo (CAROZZI, 1994, p. 598).

Os dois gigantes são heróis da mitologia celta do Ciclo do Ulster. Fergus foi um chefe militar importante e participou de batalhas míticas na Irlanda. Narrativas antigas diziam que tinha grande potência sexual e necessitava de sete mulheres para se satisfazer (VARANDAS, 2006, p. 337). A sua espada Caladbolg é a antecessora da espada do rei Artur, Excalibur. Na versão castelhana de 1526 o monstro não é nomeado e seguem os sofrimentos sofridos pela alma em seu interior, quando o anjo o deixa sozinho:

Y el ángel desapareció y quedó el alma sola, y luego en ese punto la cercaron los diablos así como canes rabiosos y la atormentaron fuertemente y desque le hubieron dado muchos tormentos la metieron en el vientre de aquella mala bestia. Cuantas penas allí sufría no hay hombre que lo pudiese pensar, $\mathbf{y}$ mucho hedor y mucho fuego y otros muchos tormentos que contar ni decir no se podrían. Y como ella yacía allí llorando sus penas y culpas y pecados y causándose así mesma por las cosas y pecados que había hecho, por los cuales sufría aquellas penas tan grande y cuando no se cató se vio fuera. $(V T, 2013$, p. 4).

O copista deixa que os ouvintes e leitores da narrativa, mas imaginassem do que visualizassem os tormentos, na medida em que apenas afirma que a alma sofreu fogo, fedor e outros muitos tormentos que não se pode contar nem dizer, aumentando o impacto dramático da descrição.

Depois disso, o ente celeste e o cavaleiro descem ainda mais, rumo ao Antigo Inferno Inferior, ou o Inferno propriamente dito, onde encontram a figura de Lúcifer, que tortura os condenados, mas é igualmente torturado numa grelha de ferro.

\section{A Visio Tnugdali e as Artes Plásticas}

De acordo com os historiadores Jean-Claude Schmitt (2002, 2007) e Jêrome Baschet (1996) as imagens tinham o propósito de educar, relembrar e comover, tendo funções devocionais, rituais, políticas, entre outras.

A imagem medieval "presentifica", sob as aparências, do antropomorfo e do familiar, o invisível no visível, Deus no homem, o ausente no presente, o passado ou o futuro no atual. Ela reitera assim, a sua maneira, o mistério da Encarnação, pois dá presença, identidade, matéria e corpo àquilo que é transcendente e inacessível (SCHMITT, 2002, p. 595)

Nesta busca de compreensão das relações entre o vísível e o invisível no medievo através da relação entre as imagens materiais e mentais, muitos estudos tem se voltado à análise da produção imagética, uma vez que as mesmas nos auxiliam à compreensão do imaginário desse período. 


\section{Notandum 42 set-dez 2016 - CEMOrOC - Feusp / IJI-Univ. do Porto \\ DOI: http://dx.doi.org/10.4025/notandum.42.1}

Várias descrições da Visio Tnugdali parecem ter inspirado as artes plásticas. Um exemplo é a figura do diabo sofrendo na grelha de ferro, tal como é mostrado numa iluminura do Livro de Horas do Duque de Berry, do século XV, inspirada na Visão de Túndalo (ZIERER; OLIVEIRA, 2010).

A Visio afirma o Príncipe das Trevas é "negro como carvão" (VT, 1895, p. 110), o que também se confirma na imagem dos irmãos Limbourg. Lúcifer é retratado por eles de forma animalesca e, por ser o Príncipe do submundo, porta uma coroa em sua cabeça.

Os demônios que o atormentam igualmente possuem aspecto animal, como descrito por autores que tratam da figura demoníaca, como Russel, Nogueira e Baschet em relação a essas criaturas. Apresentam asas de morcego, rabo e outros aspectos bestiais. Outro elemento característico da iconografia do Inferno é a sua escuridão, caracterizada por tons escuros e avermelhados, por montanhas e pelo fogo (ZIERER; OLIVEIRA, 2010, p. 56). Um aspecto que se destaca na imagem é o fato de os eclesiásticos (o que se vê através da tonsura em suas cabeças) estarem sofrendo no Inferno, sendo arrastados por diabos, o que não vemos descrito no Inferno nas versões portuguesas do manuscrito, nem na versão de Toledo de 1526. Estas suavizam os pecados dos eclesiásticos, mas nas versões latinas do século XII e em várias do século XV existe uma punição especial voltada para eles, que é o sofrimento na Besta Pássaro (ver no Quadro 1, o castigo dos luxuriosos).

Bosch parece ter se inspirado nessa Besta Pássaro, como no detalhe de O Jardim das Delícias Terrenas, que pode ser visto a seguir (figura 2):

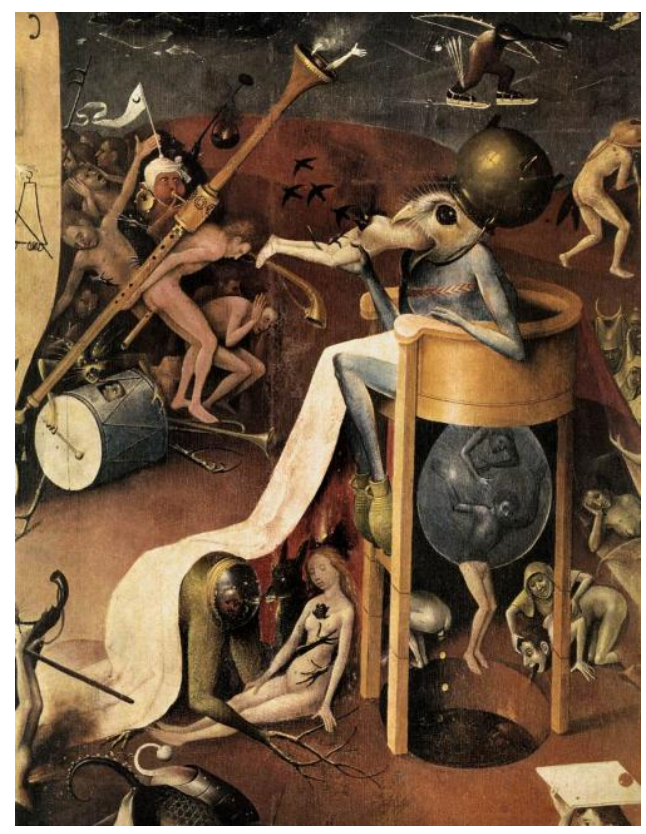

Figura 2. Bosch (El Bosco). O Jardim das Delícias Terrenas (C. 1500). Detalhe. Museu do Prado, Madrid. http://www.wga.hu/frames-e.html?/html/b/bosch/index.html. Acesso em 10/01/2015

Nesta imagem há um pássaro que come uma criatura e ao mesmo tempo defeca duas outras. As ações de comer/defecar/parir estão próximas. Essas almas "saem" da besta numa espécie de ovo transparente de onde caem num buraco ou nascem. Também um humano fora dali defeca no mesmo buraco onde as almas caem e outro vomita no mesmo local.

A besta não é mostrada exatamente como retratada no relato sobre o cavaleiro pecador, quando é descrita como tendo um pescoço de ferro, unhas de ferro e estava num lago 
gelado, onde depois de consumir as almas, as fazia nascer (ou as expelia) naquele local (VT, 1895, p. 107-108). A Visión de Don Túngano fala sobre esse animal que

Esta bestia era muy desfigurada y muy desemejada a todas las otras que antes había visto. Esta bestia tiene dos pies muy grandes, y dos alas en el cuerpo muy grandes y muy largas, el rostro como fuego, y uñas muy agudas, y le salía por la boca de su cabeza muy grandes llamas. (VT, 2013, p. 5, grifo nosso).

Além do seu tamanho gigantesco e suas grandes unhas, segundo as versões lusas, tinha também grandes chamas que saíam de sua boca, segundo a versão de 1526. Aqueles que sofrem no interior desta besta, principalmente os eclesiásticos que cometeram a luxúria, de acordo com as versões latinas, engravidam no ventre da besta e depois parem monstros por todos os membros do corpo, conforme já mencionado no Quadro 1, que os mordem até os nervos e ossos.

A versão de Toledo de 1526 não menciona que aqueles que sofrem nela são os eclesiásticos luxuriosos, mas menciona a figura dos clérigos sofrendo no interior da besta, em virtude de possuírem línguas que maldizem. Os códices portugueses 244 e 266 do Mosteiro de Alcobaça também falam da punição às más línguas, mas não nomeiam os religiosos como sendo punidos por esse castigo. Segue a descrição da Visión de Don Túngano:

Estas penas merecieron aquellos que debían ser mejores que los otros causo de ello y no lo son, porque tienen las lenguas en el maldecir sufren los muesos de las serpientes que ves, esto mismo acontece a los clérigos y doctores de la santa madre iglesia y de todos los otros prelados que gravemente pasasen y sufriesen esta pena. (VT, 2013, p. 6, grifo nosso).

Embora sofra no interior da besta, Túndalo/Túngano não chega a engravidar de monstros, pois o anjo o salva desse tormento, como podemos observar no trecho a seguir:

Entonces le desapareció el ángel, y los diablos luego la prendieron [a alma de Túngano], y la llevaron donde estaba la bestia, y se la dieron a tragar. Cuanta pena y cuanto trabajo ella allí sufría no hay hombre que lo pudiese pensar ni contar. $Y$ después la bestia la echo de su vientre, y cayó en el lago donde sufría muy gran dolor y pena. Y entonces el ángel con gran dolor volvió a ella, y le dijo: "Vente a mí, amiga mía, ca no sufrirás más estas penas" (VT, 2013, p. 6, grifos nossos).

Como podemos observar nesta passagem, o cavaleiro sofre vários castigos, mas logo depois é salvo de tormentos ainda piores pela figura do ente celestial, uma vez que após parir bestas os condenados eram mordidos por elas até os nervos e ossos, o que não chega a ocorrer com a alma do cavaleiro.

Na figura 2, Bosch, além de retratar a importante figura da Besta Pássaro, inspirada na Visio Tnugdali, mostra outros pecadores que estão sendo torturados na pintura por diabos. E até os instrumentos musicais têm a função de causar incômodo, o que se pode perceber 
através de um homem com a mão no ouvido e uma flauta introduzida no traseiro de outro condenado, uma alusão ao pecado da luxúria.

Uma representação dos castigos da Visión de Don Túngano foi realizada no século XVI por pintor anônimo, seguidor do estilo de Bosch, como pode ser visto a seguir (Figura 3):

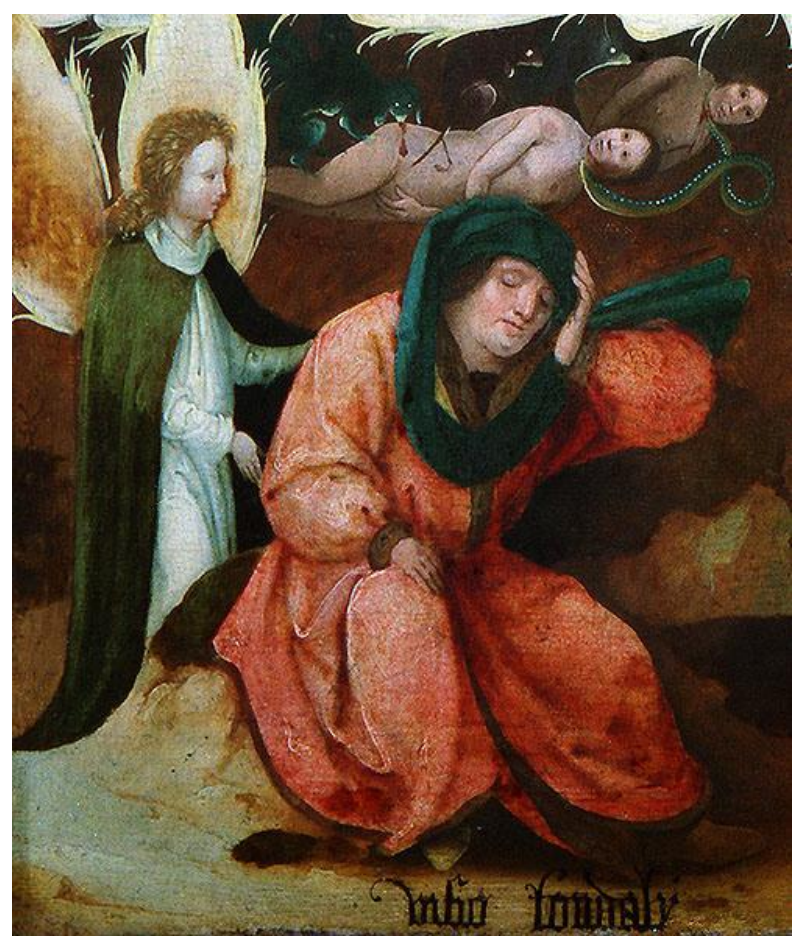

Figura 3. Seguidor de Hieronymus Bosch (1520-1530). Detalhe La Visión de Tondal. Fundación Lázaro Galdiano, Madrid, inv. 2892.

No detalhe da imagem, vemos a figura de Túndalo/Túngano/Tnugdalus/Tondal, que nessa interpretação da narrativa está dormindo, e atrás dele se encontra a figura do seu anjo protetor. Próximo dele, à direita, está escrito "Visio Tondaly", ligando diretamente a pintura com aquela narrativa. Acima do anjo e do cavaleiro adormecido, vemos um casal nu, Adão e Eva, próximo do qual estão diabos (figura 4). O casal parece estar sendo torturado por uma 


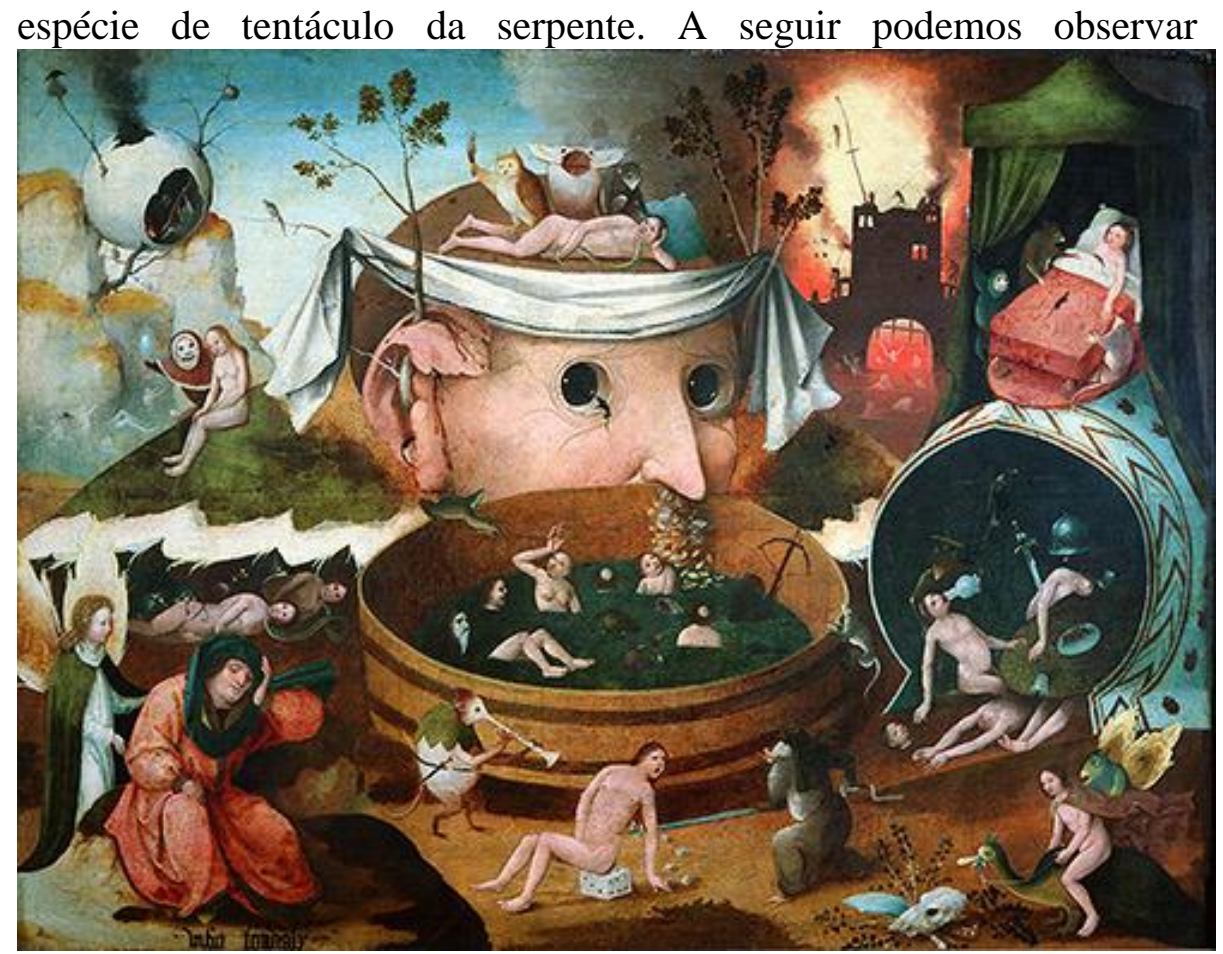

Figura 4 a pintura completa:

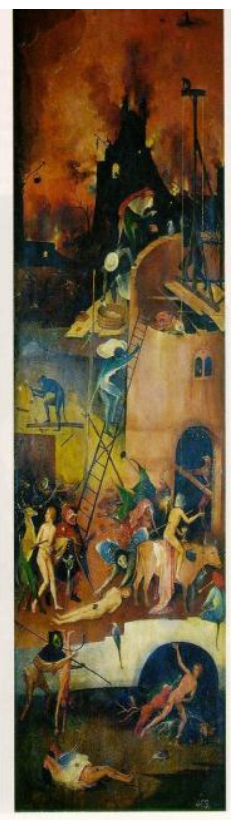

Figura 5

Figura 4. Seguidor de Hyeronimus Bosch (1520-1530). La Visión de Tondal. Inscrição em baixo, do lado esquerdo, em letras góticas Visio Tondaly. Madrid, Fundación Lázaro Galdiano, Madrid, inv. 2892.

http://museolazarogaldiano.wordpress.com/2012/11/27/vision-de-tondal-seguidor-el-bosco-bosch-museo-lazarogaldiano-interpretacion-iconografica-amparo-lopez/

Acesso em 20/01/2013.

Figura 5. Hieronymus Bosch. Detalhe do Inferno. Tríptico de Haywain. (A Carroça do feno). Museu do Prado, Madrid. (painel lateral)

Referência: Web Gallery or Art (wga)/ Triptych of Haywain (right wing)

In: http://www.wga.hu/frames-e.html?/html/b/bosch/index.html

Acesso em: 21/01/2014

A imagem (fig. 4) mostra a figura do cavaleiro, aqui numa espécie de sonho e atrás dele a figura do anjo protetor. Essa representação inspira-se na Visio, mas fornece uma livre interpretação da mesma, sem ter a obrigação de mostrar exatamente o que é contado na narrativa. No centro da imagem há uma grande cabeça com os olhos vazados, um inverso do que deveria ser a imagem divina (CECCHI, 2013, p. 128).

A cabeça está no centro da pintura e acima dela há um pano que a atravessa de um lado a outro, na altura da testa, apoiado em duas árvores, uma de cada lado. Vemos uma dessas árvores saindo da sua orelha e um rato negro entrando no seu ouvido. Em cima da cabeça um homem nu (Adão?) é torturado por uma serpente e próximo dele estão uma coruja, um macaco e o outro animal monstruoso. Num de seus olhos vazados está entrando um rato negro, símbolo da luxúria.

Do nariz saem moedas, o que representa o inverso do sopro divino e está ligado ao pecado da avareza. Elas caem em cima dos pecadores, que estão sendo castigados no interior de uma bacia. Percebemos entre esses condenados a figura de um religioso, devido à tonsura em sua cabeça. 
Há ainda outros pecados representados na pintura, como a gula e a ira, através de pessoas numa toca. $\mathrm{O}$ pecado da preguiça também está representado, através do homem que está sobre um leito (vigiado por um diabo), e sobre o qual passa outro rato. A pessoa jazida na cama também lembra o momento da morte, quando se acreditava que as almas eram julgadas. A cena faz alusão ao quadro A Morte do Avarento (c. 1490, National Gallery of Art), de Bosch, retratando um moribundo que queria levar um saco de dinheiro para o Além, motivo pelo qual seria, com toda certeza, condenado ao Inferno (ZIERER, 2010, p. 9).

O tema da proximidade da morte e do julgamento da alma, que aparece tanto na figura quanto nos quadros de Bosch, era recorrente na Baixa Idade Média, quando foram compostos livros sobre a Arte do Bem Morrer, tratando do momento da morte, e da luta de Deus e o Diabo pelas almas no momento em que a alma ia deixar o corpo. Esses livros foram ricamente ilustrados com xilogravuras (GOMBRICH, 1999, p. 282-283).

Voltando à figura 4 do seguidor de Bosch, vemos, no chão, pessoas atacadas por demônios semi-animalescos com instrumentos de tortura, como o homem sentado em cima de um dado. Quanto ao fundo da imagem, do lado direito, lembra uma casa vermelha em chamas, que aparece em outras pinturas do artista holandês, como, por exemplo, no detalhe do Tríptico de Hawain (ou Carro de Feno), num dos volantes laterais da imagem, representando o Inferno (figura 5). Essa imagem da casa em chamas, o Inferno, das figuras 4 e 5, parece ter semelhança com a Casa de Fristin, retratada na Visão de Túndalo. Nessa casa sofriam tormentos os glutões e fornicadores (ver Quadro 1). No relato sobre Túndalo, ela representa um imenso forno, que ao invés de cozer pão, assa as almas pecadoras. Uma versão do Languedoc da narrativa, afirma que esse forno pune mais fortemente os religiosos que pecaram $(V T, 1903$, p. 79$)$.

É interessante mencionar que na Visio os pecadores são torturados por objetos do cotidiano que lembram o ato de cozinhar. O pecado da luxúria e da gula se confundem, sendo as pessoas castigadas em fogões, frigideiras, fornos e na forja de Vulcano. Por isso os condenados sofrem através de espetos, são cortados, assados e transformados numa massa através de marteladas. As representações de Bosch parecem amplamente inspiradas nas descrições sobre o cavaleiro pecador.

Após visitar os espaços do Purgatório e o Inferno, onde vê Lúcifer, Túndalo atinge o Paraíso na companhia do anjo. Este local é dividido em três muros, de acordo com a pureza de seus habitantes. A primeira parte do Paraíso é o Muro de Prata, dedicado aos que não cometeram adultério no casamento. Ali há presença de beleza, sonoridade e pessoas que cantam como "cantares de órgãos" (VT, 1895, p. 114).

$\mathrm{Na}$ época medieval, o muro representa proteção e organização do espaço e é um elemento constitutivo das cidades, que erguiam muralhas com finalidade principalmente militar. O fechado está associado ao Paraíso, já o aberto, com o Inferno, ligado a órgãos como a boca e o ânus (BASCHET, 1985).

\section{O Paraíso na Visão de Túndalo}

No Paraíso, os sentimentos, ligados aos órgãos dos sentidos, são agradáveis. As paisagens são belas, os aromas são de flores, há cantos de pássaros e os habitantes do local estão alegres todo o tempo. Os habitantes estão ali de acordo com o merecimento de cada um e seguindo uma hierarquia de pureza. Após a sua passagem nos locais infernais e depois num espaço intermediário, espécie de antecâmara do Paraíso, Túngano e o anjo chegam ao Paraíso propriamente dito. 
Vejamos a seguir as características dos Muros Celestiais (Quadro 2):

\section{QUADRO 2. MUROS CELESTIAIS E SEUS HABITANTES NO PARAÍSO}

\begin{tabular}{|l|l|}
\hline MUROS & HABITANTES \\
\hline PRATA & $\begin{array}{l}\text { Os castos no casamento, as almas que repartiram } \\
\text { os seus bens com os pobres }\end{array}$ \\
\hline OURO & $\begin{array}{l}\text { Os monges e monjas, os construtores da Igreja e } \\
\text { que se sacrificaram por ela }\end{array}$ \\
\hline PEDRAS PRECIOSAS & $\begin{array}{l}\text { As nove ordens dos anjos, os Profetas da Bíblia, } \\
\text { os Apóstolos de Jesus, as virgens, S. Patrício, } \\
\text { São Malaquias }\end{array}$ \\
\hline
\end{tabular}

Percebemos que no Muro de Prata, o mais importante era não cometer o adultério, no caso dos leigos casados e realizar a caridade (repartir os bens com os pobres). No Muro de Ouro, local dos religiosos, daqueles que sofreram pela fé cristã, há uma árvore que representa a Igreja Católica. Ali a alma de Túndalo/Túngano escuta cantos "formosos e saborosos" (VT, 1895, p. 116) e sons. A harmonia é tamanha que os habitantes cantam sem mover as bocas e os instrumentos soam sem serem tocados (VT, 1895, p. 117) (grifo nosso). musicais:

Na Visión de Don Túngano, podemos observar a ênfase na descrição dos instrumentos

Y cató a todas partes, y vio muchos castillos muy hermosos, y muchas tiendas de seda y de púrpura y de escarlata y de oro y de plata compuestas a maravilla. En el coro de ellos vio órganos y sal-terios, vihuelas y guitarras, y otros muchos instrumentos que hacían sones a maravilla. (VT, 2013, p. 10, grifos nossos).

Mais uma vez é possível destacar o forte predomínio da oralidade como um elemento de harmonia paradisíaca através da menção de órgãos, saltérios, violas, guitarras, entre outros.

Por fim o Muro de Pedras Preciosas era dedicado aos cristãos mais puros. Ali estavam além das nove ordens de anjos, importantes religiosos da Irlanda, como a figura de São Patrício, introdutor do cristianismo na região, no século V. Além dele, há também a presença de S. Ruadan, patrono do mosteiro de Lorrha (Tippery) (século VI) e um dos patronos da Irlanda. Também destacamos ali a presença de três abades ligados ao movimento de Reforma na Igreja Irlandesa, partidários, portanto da Reforma Gregoriana, tal como o anônimo Marcus, produtor do relato. Esses abades eram Celestino, abade de Armagh, Malaquias (seu sucessor), que segundo a Visão de Túndalo, dava todas as esmolas que recebia aos pobres, e Christianus, abade de Louth (PONTFARCY, 2010, p. XLIII).

No Muro de Pedras Preciosas a alma viu ainda mais beleza e alegria que nos locais anteriores e além disso "esta alma ouuio palauras muy marauilhosas. e muy sanctas. per tal guisa que non conuen a nenhuun homen de as dizer" (VT, 1895, p. 118, grifo nosso). Mas, por ainda ser um pecador, Túndalo necessitava retornar, mudar o seu comportamento e contar a sua experiência aos demais. 


\section{Notandum 42 set-dez 2016 - CEMOrOC - Feusp / IJI-Univ. do Porto \\ DOI: http://dx.doi.org/10.4025/notandum.42.1}

De repente, ele sente o peso do seu corpo e acorda, logo pedindo para tomar a hóstia e se confessar, o que nos remete ao início do relato, quando ele desmaia ou entra em coma (ver figura 1). A partir do seu retorno, o cavaleiro se torna um novo homem, doa seus bens e se torna um bom cristão. De acordo com o relato:

Todos se maravillaban de las cosas que [Don Túngano] decía y de los hechos que hacía en la vida que después vivió. Por ende esto todo que habéis oído, así de las cosas del infierno y purgatorio y paraíso a nosotros mucho aprovechará si quisiéremos en ello parar mientes, porque Nuestro Señor Jesucristo como es verdadero juez ni deja mal sin pena, ni bien sin galardón. (VT, 2013, p. 12, grifos nossos).

O final da narrativa reforça o aspecto educativo da obra, enfatizando o caminho do cavaleiro pelo Inferno, Purgatório e Paraíso, sua mudança comportamental após o retorno e o fato de que cada cristão receberá o seu "galardão" de acordo com as suas ações na terra.

\section{Conclusão}

A experiência da alma percorre cinco fases ou etapas: 1- um pecador é escolhido para conhecer as dores do Inferno e glórias do Paraíso através de uma viagem terrestre, acompanhado por um guia divino, o anjo; 2- ele enfrenta dificuldades e sofrimentos num primeiro momento; 3-depois experimenta as alegrias divinas; 4- num último momento, retorna ao mundo terreno regenerado. 5- Através desta trajetória, se arrepende dos seus pecados e conta o que viu no Além-túmulo aos outros, possibilitando assim não somente a sua salvação, mas a de vários outros cristãos, através do seu exemplo (ZIERER, 2010, p. 2021).

Também é possível perceber que para as impressões serem gravadas mais fortemente na mente das pessoas, o relato apela bastante para os órgãos dos sentidos, com especial ênfase para a visão e audição, mas com a participação ativa de todas as sensações. Por isso, tudo o que acontece é visto por Túndalo/Túngano, tanto os aspectos belos do Paraíso, quanto as imagens aterrorizantes do Inferno. Ele também escuta, tanto sons agradáveis no Paraíso (música e cantos) quanto sons terríveis no Inferno (gritos e gemidos). No Paraíso, o tato é utilizado com as roupas e peças nobres utilizadas pelos eleitos (coroas, livros, copos, as próprias pedras preciosas e outros objetos de ouro), em contraste com os corpos dilacerados nos espaços de punição, através de gadanhos de ferro, espetos, martelos, fornos, pontes com pregos, entre outros tormentos. Há ainda os aromas (ligado ao órgão do olfato) e o sabor (paladar) de flores e frutos dos bons lugares, em oposição ao fedor e ingestão de enxofre nos locais ruins.

Podemos concluir através deste relato, uma série de elementos sobre o período medieval. A Visio teve uma grande influência nessa época com manuscritos em latim, em várias línguas vernáculas e também uma grande circulação nos primeiros livros impressos dos séculos XV e XVI. O autor irlandês do século XII era partidário da Reforma Gregoriana e do clã dos Mcarthy, através da presença do rei Donato, que é visto como muito generoso e que doou seus bens aos pobres, após uma grave doença.

Na melhor parte do Paraíso, também percebemos a presença de figuras importantes para o cristianismo na Irlanda, como São Patrício e São Malaquias, entre outros nomes 
importantes do cristianismo irlandês, que se encontravam no mesmo espaço que as nove ordens de anjos e em contato direto com Deus.

Já os traços pagãos da cultura irlandesa, como os antigos heróis míticos, como Fergus e Connal, do ciclo do Ulster, são agora diabolizados e se encontram como uma espécie de guardiões, na entrada da boca da besta Aqueronte, que punia os avaros.

O cavaleiro pecador passa de um primeiro momento de má conduta, ligado aos prazeres carnais, a um modelo de cristão, que conta através da oralidade a sua experiência aos demais, contribuindo para a conversão da sociedade.

A Visão de Túndalo/Visión de Don Túngano, veiculada através de vários manuscritos e textos impressos teve grande circulação tanto através da escrita quanto da oralidade, contribuindo com o papel de conversão dos cristãos. Auxiliou ainda a mensagem da Igreja fosse relida em diferentes momentos históricos, do século XII ao XVI, além de ter inspirado as artes plásticas, através de influências no trabalho de Bosch e de outros artistas do período.

\section{REFERÊNCIAS}

FONTES

História del Virtuoso Cavaleiro Dõ Túngano. Toledo, 1526. Disponível em: http://archive.is/20121230013227/slt.telam.com.ar/la-vision-de-tungano/c13. Acesso em 15/01/2014.

La Visión de Don Túngano, relato de frater Marcus. Disponível em: http://zonaliteratura.com/index.php/2012/10/21/la-vision-de-don-tungano-relato-de-fratermarcus/ Acesso em 10/12/2013.

Vision de Tundal (La Visio del Monestir de Clares Valls) In. Miquel y Planas, R. Llegendas de L’Altra Vida. Barcelona: Biblioteca Catalana, 1914, p. 35-69.

Visão de Túndalo. Ed. F. M. Esteves Pereira. Revista Lusitana, 3, 1895, p. 97-120 (Códice 244).

Visão de Túndalo. Ed. de Patrícia Villaverde. Revista Lusitana, n. s., 4, 1982-1983, p. 3852 (Códice 266).

Vision de Tindal In: Voyage de Raimon Perellos au Purgatoire de Saint Patrice: Visions de Tindal et de Saint Paul. Textes languedocienes du XV siècle. (Publiés par A. Jeanroy et A. Vignaux.) Tolouse: E. Privat, 1903, p. 57-119.

La Vision de Tondale. Textes français, anglo-normande et irlandais publiés par V.H. Friedel \& Kuno Meyer. Paris: Librarie Honoré Champion, 1907.

La Vision de Tondale. Les versions françaises de Jean de Vignay, David Aubert, Regnaud de Queux. Editées par Matia Cavagna. Paris: Honoré Champion, 2008. 
La Visión de Tundal (um viaje al purgatório, al infierno y al cielo). Traducción e introducción de José Antonio Alonso Navarro (tradução em espanhol da versão inglesa do séc. XV). In: Mutatis Mutandis, vol. 4, nº 1, 2011, p. 108-136.

The Vision of Tnugdalus. Eletronic edition in latin compiled by Beatrix Farber, com base no ms Munchen, Bayerische Staatsbibliotek, codices latini, 22254, f. 1175-1385 (século XII). Disponível em: http://www.ucc.ie/celt/published/L207009.html acesso em 27/10/2011.

\section{ESTUDOS}

BASCHET, Jérôme. Introdução: a imagem-objeto. In: SCHMITT, Jean-Claude et BASCHET, Jérôme.L'image. Fonctions et usages des images dans l'Occident médiéval. Paris: Le Léopard d'Or, 1996, p. 7-26, tradução de Maria Cristina Pereira. Disponível em: http://www.pem.historia.ufrj.br/arquivo/jerome_baschet001.pdf. Acesso em 15/08/2015.

BASCHET, Jérôme. A Civilização Feudal. Rio de Janeiro: Globo, 2006.

BASCHET, Jérôme. La Conception de l'Enfer en France au XIVe siècle: imaginaire et pouvoir. Annales. Économies. Sociétés, Civilisations. 40e année. N. 1, 1985, p. 185-207.

BASCHET, Jérome. Les Justices de l'Au-Délà. Les Représentations de L'Enfer en France et Italie (XII et Xve siècle). Rome : École Française de Rome, 1981.

BOSING, Walter. Hieronymus Bosch. Entre o Céu e o Inferno. Paisagem/Taschen, 2006. CAROZZI, Claude. Le Voyage de l'Âme dans l'Au-Delà d'Après la Littérature Latine (V-XIIIéme Siècle). Paris: École Française de Rome, 1994.

CAVAGNA, Mattia. La "Visione di Tungdal" e la Scoperta dell'Inferno. In: Studii Celtici, 2004, p. 207-260. Disponível em:

http://www2.lingue.unibo.it/studi\%20celtici/Articolo_9 \%28Cavagna\%29.pdf. Acesso em 28/02/2011.

CECCHI, Alessandra et alii (Dir.). La Renaissance et le Rêve. Bosch, Veronèse, Greco ... Paris: Musée de Luxembourg/Réunion des Musées Nationaux, 2013.

CHAS ÁGUION, Antonio. De prodigia, geografía penitencial y elocutio en la Historia del virtuoso caballero Don Túngano. Boletín de la Biblioteca de Menéndez Pelayo, $\mathrm{n}^{\circ} \mathrm{LXXXV}$, 2009, p. 17-34.

DINZELBACHER, Peter. The Way to the Other World in Medieval Literature and Art.

Folklore, Vol. 97, No. 1 (1986), pp. 70-87. Disponível em:

http://www.jstor.org/stable/1260523

FOSTER, Edward E. “The Vision of Tundale: introduction”. In: Three Purgatory Poems.

Dalamazoo, Michigan: Medieval Institute Publications, 2004.

GARSABAL, Jordi. Del Más Allá al Nuevo Mundo. Les Viajes Medievales y las Capitulaciones de Colón en el Archivo de la Corona de Aragón. Aragón: Ministerio de Educación, Cultura e Deporte, 2013. 
GOMBRICH, Ernest. História da Arte. Rio de Janeiro, LTC, 1999.

GUREVICH, A. Oral and Written Culture of the Middle Ages: Two Peasant Visions of the Late Twelfth-Early Thirteenth Centuries. In: New Literary History, v. 16, n. 1, 1984, pp. 5184.

La Visión de Tondal, obra de un seguidor de El Bosco conservada en el Museo Lázaro Galdiano. Interpretación iconográfica por Amparo López. In:

http://museolazarogaldiano.wordpress.com/2012/11/27/vision-de-tondal-seguidor-el-boscobosch-museo-lazaro-galdiano-interpretacion-iconografica-amparo-lopez/. Acesso em: 07/01/2013.

LE GOFF, Jacques. Aspectos Eruditos e Populares das Viagens ao Além na Idade Média. In: ID: O Imaginário Medieval. Lisboa: Editorial Estampa, 1994, p. 127-142.

LE GOFF, Jacques. Além. In: Dicionário Temático do Ocidente Medieval. São Paulo: EDUSC/Imprensa Oficial do Estado, 2002, v. I, p. 21-33.

LE GOFF, Jacques. O Imaginário Medieval. Lisboa: Editorial Estampa, 1994.

LE GOFF, Jacques. O Nascimento do Purgatório. Lisboa: Editorial. Estampa, 1993.

Libro de Túngano; Visión de un caballero de Ibernia. Catálogo Hipertextual de Traducciones Anónimas al Castellano. Disponível em:

http://www.catalogomedieval.com/busqueda.php?id=225. Acesso em 05/08/2015.

MIQUEL Y PLANAS, R. Llegendas de L’Altra Vida. Barcelona: Biblioteca Catalana, 1914.

NOGUEIRA, Carlos Roberto F. O Diabo no Imaginário Cristão. $2^{a}$ Ed. Bauru, SP: EDUSC, 2002.

PALMER, Nigel. Visio Tnugdali. The German and Dutch Translations and their Circulation in the Later Middle Ages. Munich und Zurich: Artemis Verlag, 1982. PALMER, Nigel F. Illustrated Printed Editions of the Visions of Tondal from the late fifteenth centuries and early sixteenth centuries. In: KREN, Thomas (Ed.). Margaret of York, Simon Marmion and the Visions of Tondal. Malibu, California: The Paul Getty Museum, 1992, p. 157-170.

PONTFARCY, Yolande de. L'au Delà au Moyen Age. Les Visions du Chevalier Tondal de David Aubert et sa Source la Visio Tundali, de Marcus. « Introduction ». Berne: Peter Lang, 2010, p. XI-XLVII.

RODRÍGUEZ BARRAL, Paulino. La Imagen de la Justicia Divina. La Retribución del Comportamento Humano en el Más Allá en el Arte Medieval de la Corona de Aragón. Tese de Doutorado. Barcelona: Universidad Autónoma de Barcelona, 2003.

RUSSEL, Jeffrey Burton. Lúcifer: O Diabo na Idade Média. São Paulo: Madras, 2003. 
SCHMITT, Jean-Claude. Imagem. In. Le Goff, Jacques. SCHMITT, Jean-Claude (coord.) Dicionário Temático do Ocidente Medieval. V. I. Trad. de Hilário Franco Júnior. São Paulo/ Bauru: Imprensa Oficial/ EDUSC, 2002, p.591-605.

SCHMITT, Jean-Claude. O Corpo das Imagens. São Paulo: EDUSC, 2007.

SCHMITT, Jean-Claude. Os Vivos e os Mortos na Sociedade Medieval. São Paulo: Companhia das Letras, 1999.

VARANDAS, Angélica. Mitos e Lendas Celtas - Irlanda. Lisboa: Livros e Livros, 2006.

WIECK, Roger. The Visions of Tondal and the Visionary Tradition in the Middle Ages. In: KREN, Thomas e WIECK, Roger (Eds.). The Visions of Tondal from the Library of Margaret de York. Malibu, Los Angeles: Paul Getty Museum, 1990, p. 3-7.

ZIERER, Adriana M. S. Oralidade, Ensino e Imagens na Visão de Túndalo. In: Domínios da Imagem, (UEL), Londrina, Ano III, n. 6, maio 2010, p. 7-22. Disponível em: http://www.uel.br/revistas/dominiosdaimagem/index.php/dominios/article/view/83. Acesso em: 15/06/2015.

ZIERER, Adriana; PEREIRA, Solange. Diabo versus Salvação na Visão de Túndalo. Opsis, (UFG), Catalão, v. 10, n. 2, p. 43-58, 2010.

http://www.revistas.ufg.br/index.php/Opsis/article/view/11234. Acesso em 20/01/2015. 